\title{
Caracterização morfométrica de frutos e sementes e aspectos morfológicos da germinação e plântula de mangaba (Hancornia speciosa Gomes) nativa da savana \\ amapaense
}

\author{
Morphometric characterization of fruits and seeds and morphological aspects of mangaba \\ (Hancornia speciosa Gomes) germination and seedlings native to the savanna in Amapá state \\ Caracterización morfométrica de frutos y semillas y aspectos morfológicos de la germinación y \\ plántula de mangaba (Hancornia speciosa Gomes) nativa de la Savana de Amapá
}

Recebido: 28/09/2021 | Revisado: 03/10/2021 | Aceito: 06/10/2021 | Publicado: 10/10/2021

Auriane Oliveira Dias
ORCID: https://orcid.org/0000-0001-7701-6092
Universidade do Estado do Amapá, Brasil
E-mail: auriane9125@gmail.com
Paulo Rodrigues de Melo Neto
ORCID: https://orcid.org/0000-0002-9062-628X
Instituto Nacional de Pesquisas da Amazônia, Brasil
E-mail: paulordgsneto@gmail.com
Alison Pereira de Magalhães
ORCID: https://orcid.org/0000-0002-8058-256X
Universidade do Estado do Amapá, Brasil
E-mail: alisonmagalhaes429@gmail.com
Salustiano Vilar da Costa Neto
ORCID: https://orcid.org/0000-0002-1459-3658
Instituto de Pesquisas Científicas e Tecnológicas do Estado do Amapá, Brasil
E-mail: salucostaneto@ gmail.com
Zenaide Palheta Miranda
ORCID: https://orcid.org/0000-0002-8119-9239
Universidade do Estado do Amapá, Brasil
E-mail: zenaide.miranda@ueap.edu.br

\begin{abstract}
Resumo
O objetivo deste estudo foi descrever e caracterizar a morfometria dos frutos e sementes e os aspectos morfológicos da germinação e plântula de Hancornia speciosa nativa da savana amapaense. Adotou-se uma amostragem de 119 frutos e 500 sementes, para determinar as dimensões dos frutos e sementes foi mensurado comprimento longitudinal, largura, diâmetro equatorial, massa das sementes por fruto e número de sementes por fruto. Para descrição das fases do desenvolvimento pós-seminal, foram utilizadas 200 sementes dispostas em oito bandejas plásticas com substrato areia em local parcialmente sombreado com irrigação diária pela manhã e pela tarde. As relações entre as variáveis foram determinadas a partir do coeficiente de relação de Spearman (rS). O fruto é do tipo carnoso, do tipo baga, com formato variado e coloração amarelo-escura. As sementes são discoides, achatadas e de coloração castanho-claro. As características biométricas dos frutos e sementes da mangaba apresentaram grande variação, especialmente em relação ao peso e o número de sementes por frutos. A germinação ocorre em alta taxa e é do tipo epígea criptocotiledonar, possuindo boa viabilidade e rapidez para germinação. As plântulas possuem eófilos simples, opostos de ápice acuminato e base atenuada.
\end{abstract}

Palavras-chave: Fruto nativo; Cerrado; Amazônia.

\begin{abstract}
The aim of this study was to describe and characterize the morphometry of fruits and seeds and the morphological aspects of mangaba (Hancornia speciosa) germination and seedlings native to the savanna in Amapá, Brazil. A sampling of 119 fruits and 500 seeds was performed to determine the dimensions of the fruits and seeds, longitudinal length, width, equatorial diameter, mass of seeds per fruit and number of seeds per fruit. Next, 200 seeds were used to describe the post-seminal development stages, being arranged in eight plastic trays with sand substrate in a partially shaded place with daily irrigation in the morning and in the afternoon. The relationships between the variables were determined from the Spearman's rank correlation coefficient $(\mathrm{rS})$. The fruit is a berry and fleshy, with varied shape and a dark yellow color. The seeds are discoid, flat and light brown in color. The biometric characteristics of $H$. speciosa fruits and seeds showed great variation, especially in relation to weight and number of seeds per fruit.
\end{abstract}


Germination occurs at a high rate and is cryptocotyledonary epigeal, having good viability and speed for germination. Seedlings have simple eophylls, opposite an acuminate apex and attenuated base.

Keywords: Native fruit; Cerrado; Amazon.

\section{Resumen}

Este estudio tuvo por objetivo describir y caracterizar la morfometría de frutos y semillas y los aspectos morfológicos de la germinación y plántula de Hancornia speciosa originaria de la sabana de Amapá. Se adoptó un muestreo de 119 frutos y 500 semillas, para determinar las dimensiones de los frutos y semillas se midió la longitud longitudinal, ancho, diámetro ecuatorial, masa de semillas por fruto. Para describir las etapas del desarrollo post-seminal, se utilizaron 200 semillas, dispuestas en ocho bandejas de plástico con sustrato arena en un lugar parcialmente elevado con riego diario por la mañana y por la tarde. Las relaciones entre las variables se determinaron a partir del coeficiente de relación de Spearman (rS). El fruto es del tipo carnoso, del tipo baya, con forma variada y color amarillo-oscuro, las semillas son planas y de color marrón claro. Las características biométricas de los frutos y semillas de $H$. speciosa mostraron una gran variación, especialmente en relación al peso y el número de semillas por fruto la germinación ocurre a una tasa alta y es del tipo Epigia criptocotiledonaria, de buena viabilidad y velocidad de germinación. Las plántulas tienen eófilos simples, ápice puntiagudo opuesto y base atenuada.

Palabras clave: Fruta nativa; Cerrado; Amazonia.

\section{Introdução}

Hancornia speciosa Gomes, popularmente conhecida como mangaba pertencente à família Apocynaceae é uma planta frutífera de regiões tropicais que cresce espontaneamente em zonas litorâneas do Nordeste e Norte, e nas diversas regiões do bioma Cerrado do Brasil (Soares et al., 2005; Lima \& Scariot, 2010; Rabelo \& Silva, 2015).

A mangaba é perene e semi-decidual de tamanho médio com altura que varia de 2 a 15 metros (Monachino, 1945; Souza \& Lorenzi, 2006). Frequentemente, desenvolve-se em solos pobres e arenosos, especificamente na região do cerrado e nas planícies costeiras caracterizadas por baixa matéria orgânica, alta acidez e com baixa disponibilidade de nutrientes (Soares et al., 2005).

Está entre as dez espécies selecionadas como de altíssima prioridade de conservação pelo programa Plantas do Futuro do CNPq/Banco Mundial/Global Environment Facility /Ministério do Meio Ambiente (MMA)/Probio coordenado pelo MMA, com potencial de uso imediato entre as fruteiras nativas da região Nordeste (Ferreira et al., 2005).

A espécie representa um papel importante no contexto socioeconômico, pois juntamente com outras fruteiras valor potencial, crescem na mesma paisagem e densidade, com produção suficiente para justificar um ganho econômico para o pequeno produtor (Ganga, 2008; Mota et al., 2014).

No estado do Amapá nas áreas de savana foram localizadas populações nativas de H. speciosa (Freitas 2012; Costa Neto et al., 2017), e diferente das demais áreas de savanas amazônicas, as savanas amapaenses apresentam fisionomias bastante similares aquela encontrada no cerrado do planalto central brasileiro (IBGE, 2012). No entanto, existe a ameaça da expansão da produção de grãos no estado, como a soja (Pedrada \& Santos, 2014), assim a espécie vem sofrendo com redução de suas áreas de ocorrência natural (Freitas, 2012; Yokomizo et al., 2016).

Apesar da importância econômica e ambiental desse táxon, na literatura, existem poucos estudos sobre a espécie, principalmente em relação às características morfológicas e biométricas dos frutos e sementes de espécies do gênero Hancornia tornando-se ainda muito mais restritos, quando se considera a espécie H. speciosa (Ganga et al., 2010; Almeida et al., 2016). Portanto objetivou-se com o presente trabalho caracterizar a morfometria dos frutos e sementes e os aspectos morfológicos da germinação e plântula de Hancornia speciosa nativa da savana amapaense. 


\section{Metodologia}

\subsection{Coleta, processamento e análise do material}

Os frutos maduros foram coletados de uma população de $H$. speciosa, localizadas em uma área de savana no município de Macapá-AP, em dezembro de 2020. A coleta ocorreu abaixo da copa de 50 matrizes, posteriormente foram armazenados em bandejas de isopor e transportados ao Laboratório de Sementes Florestais da Universidade do Estado do Amapá (UEAP), Macapá, Amapá - Brasil, para serem beneficiados.

Para a caracterização e análise morfológica, com frutos em estágio de maturação fisiológica, considerou-se os aspectos externos, como tipo, formato e coloração do pericarpo conforme Vidal e Vidal (2006) e Barroso et al. (1999).

Para a caracterização biométrica dos frutos frescos foram mensurados comprimento longitudinal (CL) e o diâmetro equatorial (DE) dos frutos, determinados com auxílio de um paquímetro digital (Cruz; Carvalho \& Leão, 2001; Cruz \& Carvalho, 2003). A mensuração da massa fresca (MF) foi determinada a partir de uma balança analítica com precisão de 0,0001 g, e o volume do fruto (V) a partir do volume de água deslocado após a imersão do fruto em béquer 150 ml. Para estimar a massa de 1000 sementes foram utilizadas oito amostras de 100 sementes conforme recomendação de Brasil (2009).

Após a mensuração, os frutos foram despolpados manualmente e lavados em água corrente para retirada do excesso de polpa que envolve a semente e uma amostra de 500 sementes foram retiradas aleatoriamente dos frutos despolpados para determinar as dimensões: comprimento longitudinal (CLS), largura (LS), diâmetro equatorial (DES), massa das sementes por fruto (MSF) e avaliar o número de sementes por fruto (NS).

\subsection{Germinação e descrição da plântula}

As sementes de H. speciosa foram expostas para secagem à sombra por um período de 24 horas após o processo de assepsia, conforme Santos, Ferreira e Coimbra (2021) em temperatura ambiente antes da semeadura. Para descrição das fases do desenvolvimento pós-seminal, foram utilizadas 200 sementes dispostas em oito bandejas plásticas com substrato areia em local parcialmente sombreado com irrigação diária pela manhã e pela tarde.

A caracterização do estágio de plântula foi realizada selecionando-se as mais vigorosas e analisando: o sistema radicular, o epicótilo, hipocótilo e o eófilos. Os eventos morfológicos foram registrados diariamente através de fotografias, por um período de quarenta dias.

\subsection{Análises de dados}

Os dados foram submetidos à análise estatística para determinação da média, desvio padrão, coeficiente de variação, assimetria e curtose, valor máximo e mínimo e correlação de Pearson. Os valores de referência adotados para o coeficiente de assimetria foram: $S<0$, distribuição assimétrica a esquerda e $S>0$, distribuição assimétrica a direita e para o coeficiente de curtose foram: $\mathrm{K}>3$, distribuição mais "afilada" que a normal (leptocúrtica) e $\mathrm{K}<3$, distribuição mais achatada que a normal (platicúrtica). Na avaliação de correlações entre variáveis, consideraram-se as seguintes classes de correlação: forte $(0,8 \leq \mathrm{P}<$ 1), moderada $(0,5 \leq \mathrm{P}<0,8)$, fraca $(0,1 \leq \mathrm{P}<0,5)$ e ínfima $(0<\mathrm{P}<0,1)$ conforme Santos (2010). Para as análises foi utilizado o programa estatístico R Studio versão 4.0.2 (R Core Team, 2020).

\section{Resultados}

\subsection{Morfometria de Frutos e Sementes}

O fruto da mangaba é do tipo baga, variando de frutos oblongos e redondos e a maioria dos frutos apresentou coloração amarelo-escuro com manchas avermelhadas. Os valores médios e desvio padrão de comprimento e diâmetro dos frutos de mangaba foram respectivamente de 37,32 $\pm 5,70 \mathrm{~mm}$ e 27,76 \pm 4,41 $\mathrm{mm}$ (Figura 2 - a), apresentando uma 
distribuição normal. A massa fresca do fruto apresentou valor médio de 15,41 g, e valores máximo e mínimo entre 48,49 g e 3,77 g. As sementes são achatadas e discoides, com coloração castanho-claro. Apresentaram comprimento médio de 9,56 mm, largura média de 7,86 mm, e espessura média de 3,84 mm (Figura 2 - b).

Figura 2 - Dimensões biométricas de fruto e sementes de H. speciosa, (a) comprimento e diâmetro médio dos frutos, (b) comprimento, largura e espessura média das sementes.

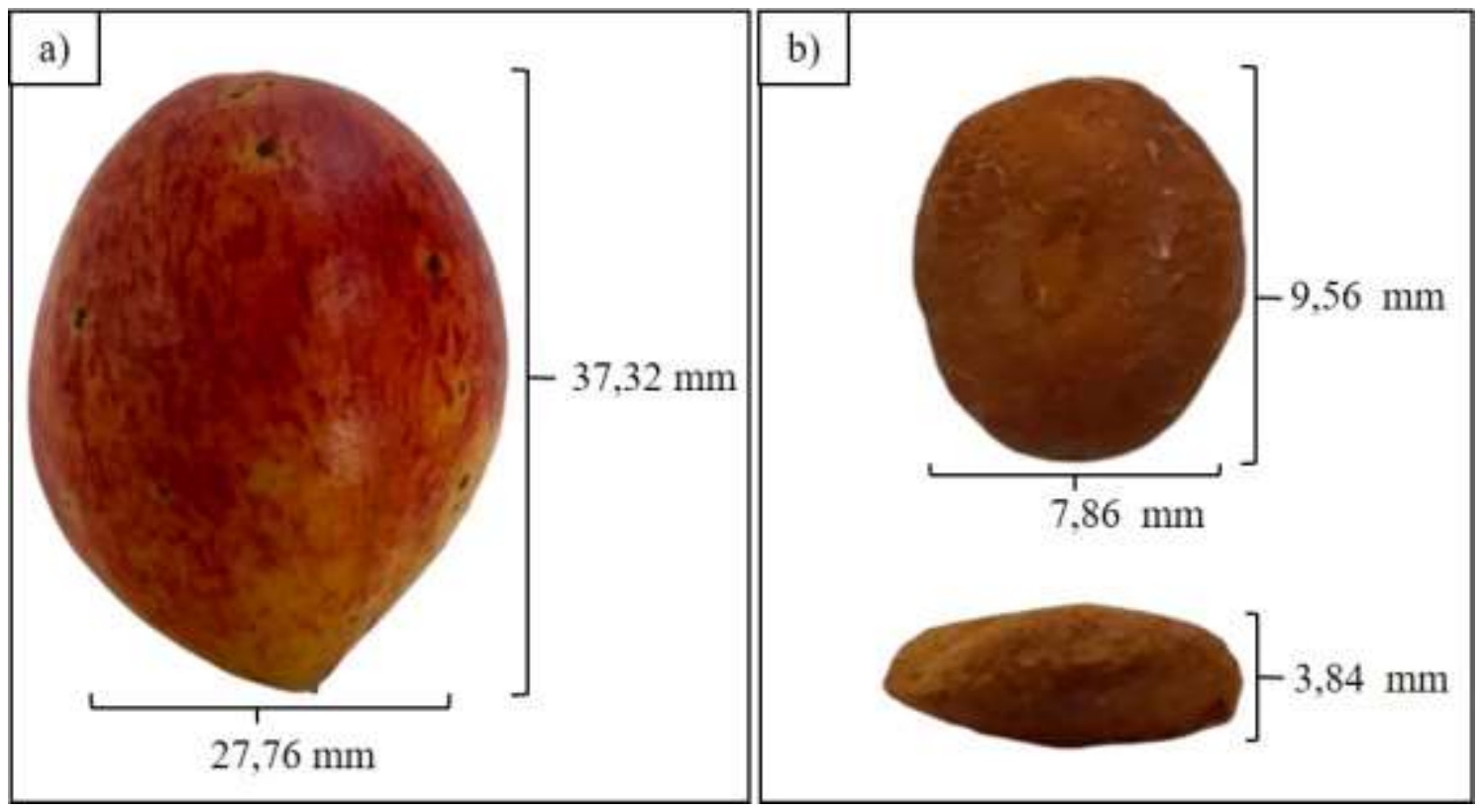

Fonte: Autores.

Foi observado através do teste Shapiro-Wilk que os dados de massa fresca, volume e número de sementes por fruto não se ajustam a distribuição normal (p<0,05). A média do número de sementes por fruto foi de 5,69 \pm 5,30, sendo que em $13,4 \%$ dos frutos apresentaram apenas uma semente fruto, característica biométrica com a maior amplitude de variação nos frutos, que acabou resultando em $93,14 \%$ de coeficiente de variação, seguido pelo volume e massa fresca com $45,14 \%$ (Tabela 1).

Ao analisar o coeficiente de variação (CV), os valores de comprimento e diâmetro dos frutos com pouca variação. Por outro lado, as variáveis massa fresca dos frutos e o número de sementes apresentaram elevado CV, indicando alta variabilidade.

As características biométricas dos frutos foram positivas com relação à assimetria (S), indicando comportamento assimétrico à direita, ou seja, na amostra analisada os frutos com menor massa fresca, menor comprimento e menor diâmetro encontram-se em maior quantidade.

Ao contrário dos frutos, as sementes tiveram distribuição assimétrica para a esquerda e negativa, evidenciando predominância de sementes com maior valor de massa fresca, maior comprimento, maior diâmetro e espessura na amostra analisada. A assimetria dos parâmetros avaliados nas sementes apresenta valores próximos de zero, o que indica uma aproximação da distribuição normal (Tabela 1). Já entre as características biométricas das sementes o coeficiente de variação manteve-se com a variabilidade maior de $21,4 \%$ para massa fresca.

Esse resultado indica que as sementes apresentaram homogeneidade quanto às características biométricas avaliadas, pois apresentaram menores valores de desvio padrão e coeficiente de variação e valores próximos de média e amplitude total. 
Quanto ao coeficiente de curtose, os valores apresentados de massa fresca dos frutos, volume dos frutos, número de sementes e espessura das sementes foram de $\mathrm{K}>3$, ou seja, leptocúrtica, mostrando uma concentração de valores ao redor da média. Os valores onde $\mathrm{K}<3$ indicando valores dispersos ao redor da média, foram para as medidas das variáveis comprimento, diâmetro dos frutos e das sementes (Tabela 1).

Tabela 1 -Médias das características biométricas dos frutos e sementes de Hancornia speciosa Gomes $n$ : tamanho amostral, $C V$ : coeficiente de variação, $S$ : assimetria, $K$ : curtose.

$\begin{array}{lllllllll}\text { Características biométricas } & \mathrm{n} & \text { Máximo } & \text { Mínimo } & \text { Média } \pm \text { erro padrão } & C V(\%) & S & K\end{array}$

\section{FRUTOS}

\begin{tabular}{cccccccc} 
Massa fresca (g) & 119 & 48,49 & 3,77 & $15,41 \pm 6,95$ & 45,143 & 1,346 & 3,594 \\
Comprimento (mm) & 119 & 55,28 & 24,64 & $37,32 \pm 5,70$ & 15,280 & 0,439 & 0,601 \\
Diâmetro transversal (mm) & 119 & 41,78 & 17,33 & $27,76 \pm 4,41$ & 15,917 & 0,199 & 0,101 \\
Volume $\left(\mathrm{cm}^{3}\right)$ & 119 & 50,00 & 2,50 & $14,73 \pm 7,34$ & 49,855 & 1,436 & 3,837 \\
Número de sementes (unid.) & 119 & 35,00 & 1,00 & $5,69 \pm 5,30$ & 93,142 & 3,429 & 14,510 \\
\hline SEMENTES & & & & & & & \\
Massa fresca (g) & 500 & 0,277 & 0,093 & $0,205 \pm 0,044$ & 21,474 & $-0,886$ & 0,639 \\
Comprimento (mm) & 500 & 13,760 & 6,060 & $9,559 \pm 1,035$ & 10,830 & $-0,464$ & 1,059 \\
Diâmetro (mm) & 500 & 9,900 & 5,100 & $7,860 \pm 0,768$ & 9,777 & $-0,442$ & 0,471 \\
Espessura (mm) & 500 & 7,740 & 1,080 & $3,842 \pm 0,487$ & 12,683 & $-0,567$ & 12,574 \\
\hline
\end{tabular}

Fonte: Autores.

Nas análises de correlação de Spearman para todos os parâmetros avaliados relacionados a frutos, houve correlação significativa positiva $(\mathrm{P}<0,05)$, demonstrando que frutos maiores têm também maior massa, assim como frutos com maior comprimento apresentam maior diâmetro (Tabela 2).

Houve correlação para os parâmetros avaliados relacionados às sementes, exceto para massa fresca x comprimento das sementes e massa fresca $\mathrm{x}$ espessura das sementes. Foram observadas correlações negativas para massa fresca $\mathrm{x}$ comprimento/ massa fresca $\mathrm{x}$ largura das sementes e massa fresca $\mathrm{x}$ espessura, assim os frutos com maior número de sementes e frutos com maior massa de sementes tem menor conteúdo de polpa. Essa caracterização morfométrica é importante para formação de um banco de germoplasma com caracteres de interesse em aumentar a produtividade e assim subsidiar estudos relevantes para a conservação da espécie. (Tabela 2). 
Tabela 2 -Correlação de Spearman (rS) entre as variáveis biométricas dos frutos e sementes. * $=p<0,001$; ns $=$ não significativo.

\begin{tabular}{|c|c|}
\hline Correlações & $r S$ \\
\hline \multicolumn{2}{|l|}{ Frutos } \\
\hline Massa fresca x Comprimento & $0,851 *$ \\
\hline Massa fresca x Diâmetro & $0,943^{*}$ \\
\hline Comprimento x Diâmetro & $0,756^{*}$ \\
\hline Massa/Compr./Diâm. do fruto x Número de Sementes & $0,796 * / 0,605 * / 0,714^{*}$ \\
\hline \multicolumn{2}{|c|}{ Sementes } \\
\hline Massa fresca x Comprimento & $-0,014^{\mathrm{ns}}$ \\
\hline Massa fresca x Largura & $-0,348^{\mathrm{ns}}$ \\
\hline Massa fresca $\mathrm{x}$ Espessura & $-0,024^{\mathrm{ns}}$ \\
\hline Comprimento x Largura & $0,775^{*}$ \\
\hline Comprimento x Espessura & $0,428 *$ \\
\hline
\end{tabular}

Fonte: Autores.

\subsection{Morfologia da germinação}

A germinação caracteriza-se como epígea, fanerocotiledonar. Em média, sete dias após a instalação do experimento germinativo a radícula rompe o tegumento da testa, inicialmente apresenta-se em uma cor esbranquiçada, curta, cilíndrica e glabra. À medida em que se desenvolve, a radícula vai adquirindo um tom pigmentado puxado para a cor amarelo-creme. O hipocótilo é curto, avermelhado e espesso (Figura 2), com a presença de cotilédones pedicelados e envolvidos pelos tegumentos da semente até o seu desprendimento.

Figura 3 - Detalhes do processo germinativo de H. speciosa. a) emissão do hipocótilo; b) emissão da radícula (nove dias após a semeadura); c) alongamento da raiz primária e emissão do epicótilo (dezesseis dias após a semeadura); d) raízes secundárias e desenvolvimento dos eófilos (vinte e um dias após a semeadura). ef - eófilos; ep - epicótilo; hp - hipocótilo; rd - radícula; rp - raiz primária; rs - raiz secundária.

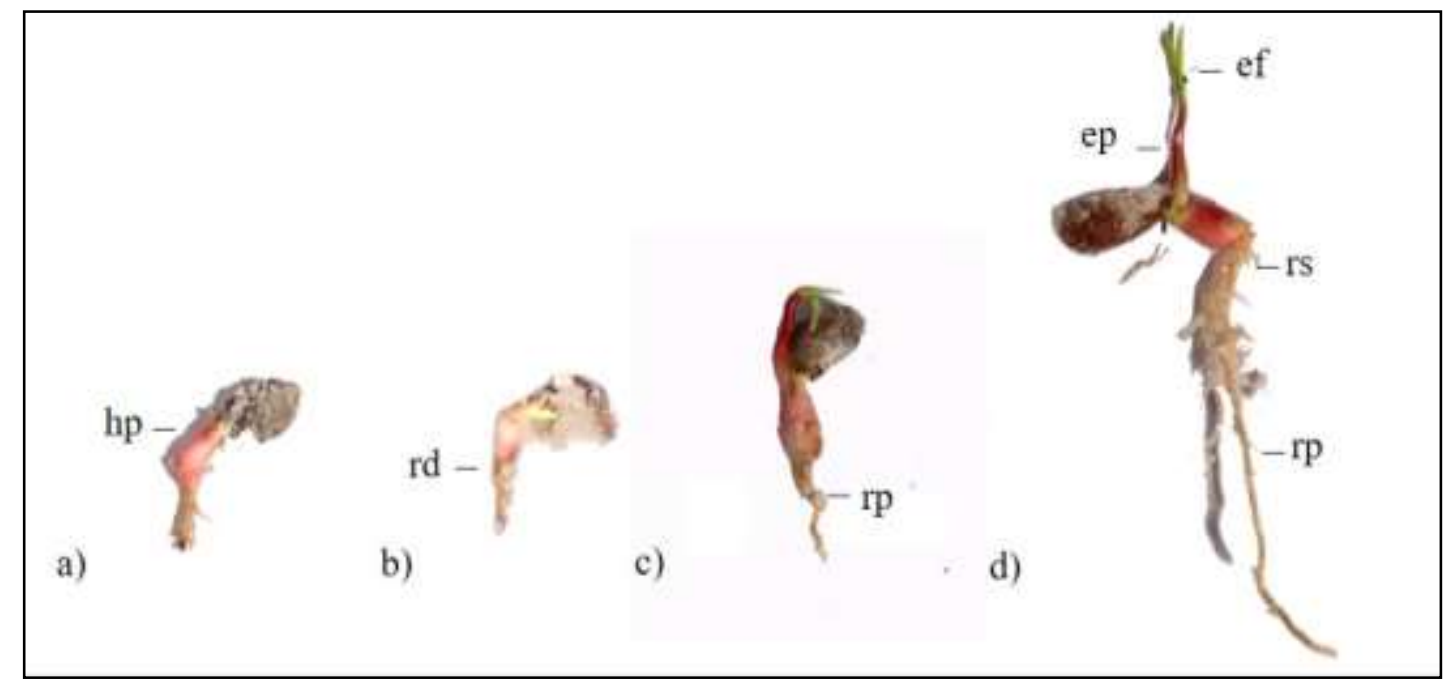

Fonte: Autores. 


\subsection{Morfologia da plântula}

O sistema radicular caracteriza-se como pivotante com raiz primária axial, fina, cilíndrica, sinuosa, com numerosas raízes secundárias que são cilíndricas, sinuosas, delgadas abundantes e bastantes ramificadas que assim como a raiz primária, apresentam base mais grossa que vai afinando no sentido do ápice. O coleto não é perceptível, há apenas uma diferença de cor entre o hipocótilo que é avermelhado e o sistema radicular que se apresenta na cor amarelo-creme. O hipocótilo é epígeo, reto, espesso, curto, suberbáceo, textura lisa, coloração avermelhada na base e mais alaranjada no ápice.

Os cotilédones apresentam dois pares laterais, são ovais e foliáceos, localizam-se no ápice do hipocótilo e são envolvidos pelo tegumento das sementes que em média de 20 dias após a emissão da radícula, já se desprende dos cotilédones. O epicótilo é cilíndrico, longo e inicialmente apresenta-se na cor verde clara, que em poucos dias torna-se vermelho claro, tornando-se gradativamente mais pigmentando, é comum a presença de látex nesta região, assim como o hipocótilo e nas folhas (Figura 4 - a).

As folhas primárias, também conhecidas como eófilos ou primeiro par de folhas já podem ser observadas aos quatorze dias após o início da germinação e caracterizam-se por serem simples, verdes de mesma tonalidade nas faces adaxial e abaxial, filotaxia oposta, presença de apenas uma nervura principal, presença de pecíolos curtos, verdes, delgados, lisos e cilíndricos (Figura $4-b, c)$.

Figura 4 - Detalhes da plântula de H. speciosa (quarenta e seis dias após a semeadura) (a) ct - cotilédone; ef - eófilos; ep epicótilo; hp - hipocótilo; rp - raíz primária; rs - raíz secundária; tg - tegumento. b) - face adaxial do eófilo; c) - face abaxial e detalhe do eófilo. aacu - ápice acuminado; bat: base atenuada; np: nervura principal.

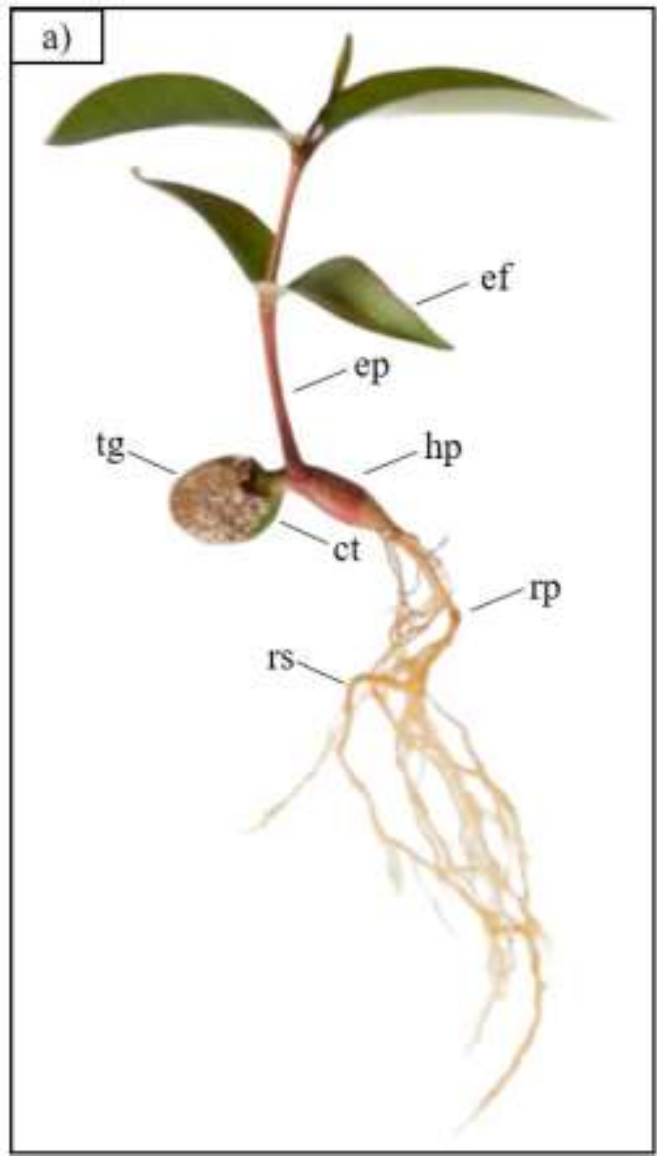

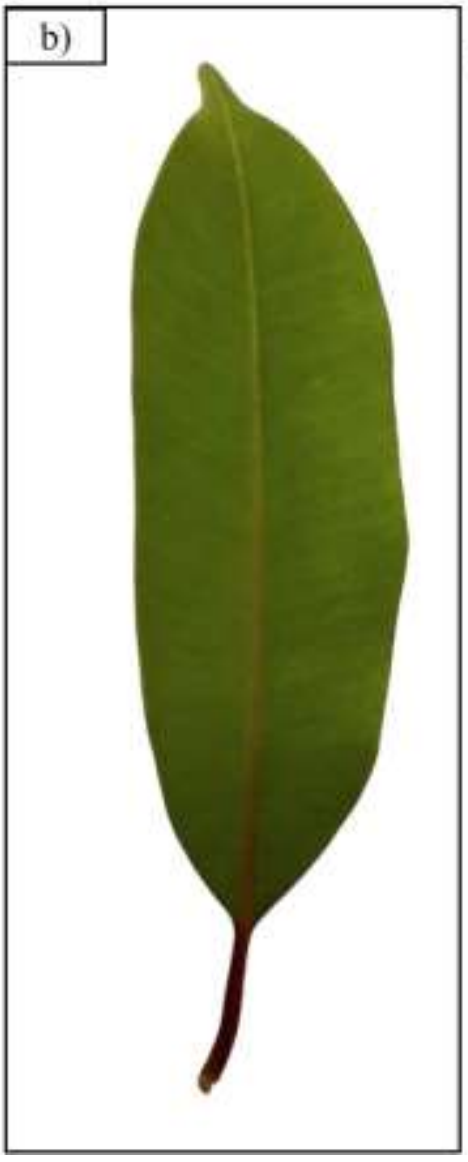

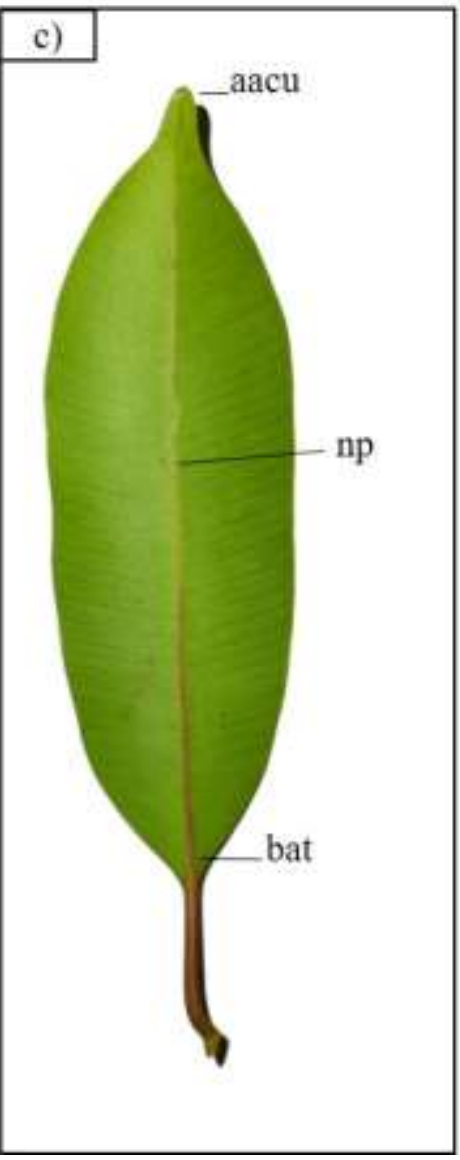

Fonte: Autores. 


\section{Discussão}

\subsection{Morfometria de fruto}

O fruto de mangaba possui tamanho, forma e cores variadas, geralmente elipsoidal ou arredondada, amarelada ou esverdeada com pigmentação vermelha ou sem pigmentação (Vieira et al., 2010, Ferro et al., 2015). Esses resultados corroboram com vários estudos para as populações do Nordeste e Centro Oeste do Brasil com valores aproximados entre 31,12 mm e 38,78 mm (Moura et al., 2002; Ganga et al., 2010; Freitas, 2012; Nascimento et al., 2014; Ferro et al., 2015; Perfeito et al., 2015; Freitas, 2012; Vieira et al., 2017; Nunes, 2018; Pinheiro et al., 2018; Santos et al, 2018; Muniz et al., 2019). Valores superiores aos encontrados neste estudo foram de Vieira (2011), para os estados de Goiás e Mato Grosso com valores médios de comprimento, largura e massa fresca de 44,7mm, 40,1 mm e 42,7g; e 44,57mm, 41,59 mm e 46,49 g.

Os frutos com maior comprimento apresentam maior diâmetro, a correlação também foi positiva na análise dos parâmetros biométricos de frutos de butiazeiro, murici e coquinho-azedo (Pedron, Menezes \& Menezes, 2004; Gusmão; Ferreira \& Fonseca, 2006; Moura et al., 2010).

Sabe-se que as variações nas características dos frutos são influenciadas também por fatores ambientais, como a disponibilidade de água, que é um fator essencial para a produção de frutos carnosos (Tabarelli, Vicente \& Barbosa, 2003), e consequentemente reflete na massa fresca total dos frutos.

Para o número médio de sementes por fruto foram inferiores aos encontrados por Moura et al. (2002), Ganga et al. (2010), Vieira (2011), Freitas, (2012), Gonçalves et al. (2013), Nunes (2018) e Muniz et al. (2019). E semelhantes aos valores de Lúcio et al. (2019) e Zuffo et al. (2019), com valores de 5,77 e 4,14.

Estas diferenças sugerem que o número médio de sementes por frutos provavelmente não é influenciado pelo ambiente, mas sim determinado pelo potencial biológico (autoincompatibilidade) da espécie para a produção de sementes (Carvalho et al., 1997). As variações de peso dos frutos podem ser decorrentes da variabilidade genética ou das variações ambientais devido às diferentes localidades geográficas (Vieira \& Gusmão, 2008; Santos et al., 2009).

\subsection{Morfometria da semente}

Lederman et al. (2000) e Santos et al. (2018) descrevem as mesmas características para as sementes de mangaba, mas destacam a irregularidade no contorno dessas sementes, além de serem recalcitrantes.

Zuffo et al. (2012) avaliaram as características biométricas das sementes da mangaba e obtiveram as seguintes médias: 9,43 mm de comprimento, 3,42 $\mathrm{mm}$ de espessura e 7,35 $\mathrm{mm}$ de diâmetro, valores próximos aos encontrados nesse estudo. Esta similaridade fenotípica indica que a caracterização biométrica das sementes pode ser aplicada como uma ferramenta importante na taxonomia e identificação de variedades. Em suma, as variáveis biométricas analisadas não apresentam divergências significativas com outros trabalhos realizados em populações naturais do Nordeste.

Valores próximos ao da área foram encontrados por Gonçalves et al. (2013) e Zuffo et al. (2019) com valores médios para comprimento 9,42 e 9,87, largura 7,35 e 9,41 e espessura 3,42 e 4,93. Foi possível observar em estudos no Rio Grande do Norte, Tocantins e Mato Grosso valores maiores em comprimento médio, que variam entre 10,47mm a 11,09mm, de largura entre 8,18mm a 8,9mm, e espessura 3,01mm a 4,2mm (Pinheiro et al., 2018; Lúcio et al., 2019 e Santos et al., 2018). Nas espécies tropicais existe uma grande variabilidade relativa ao tamanho dos frutos, número de sementes por frutos e massa de sementes (Cruz, Carvalho \& Leão, 2001; Cruz \& Carvalho, 2003; Gusmão, Vieira \& Fonseca, 2006).

Houve correlação para os parâmetros avaliados relacionados às sementes, exceto para massa fresca x comprimento das sementes e massa fresca x espessura das sementes. A correlação entre o comprimento e diâmetro das sementes apresentou valor mais elevado em relação aos demais parâmetros correlacionados (Tabela 2) corroborando com Gonçalves et al. (2013). 
Conforme esperado, foram observadas correlações negativas massa fresca x comprimento das sementes $(-0,014)$ e entre a massa fresca $\mathrm{x}$ espessura das sementes $(-0,024)$, diferente dos valores encontrados por Lúcio et al. (2013) em estudo sobre populações naturais do RN: 0,637 para massa fresca x comprimento das sementes e 0,464 para massa fresca x espessura das sementes, observou-se que frutos com maior rendimento de polpa as sementes contribuem menos com a massa total dos frutos.

\subsection{Morfologia da plântula}

Para Camargo et al. (2008), geralmente quando se trata de germinação epígea, o hipocótilo tende a se desenvolver consideravelmente. Entretanto, segundo este mesmo autor, há casos de hipocótilos mais espessos, pois recebem as reservas do endosperma. O hipocótilo se torna mais espesso em alguns casos de espécies de germinação epígea porque as reservas do endosperma podem ser transferidas para ele (Camargo et al., 2008).

Duke (1965) considera germinação como epígea, fanerocotiledonar quando os cotilédones emergem dos envoltórios das sementes. Pode-se verificar o mesmo tipo de germinação para outras espécies pertencentes à família Apocynaceae, como Aspidosperma australe Müll. Arg. (Matheus et al., 2008) e Aspiclosperma spruceanum BENTH. EX MULL. ARG. (Freitas, 2008).

\section{Conclusão}

As características biométricas dos frutos e sementes da mangaba apresentaram grande variação, especialmente em relação ao peso e o número de sementes por frutos. A germinação ocorre em alta taxa e é do tipo epígea criptocotiledonar, possuindo boa viabilidade e rapidez para germinação. As plântulas possuem eófilos simples, opostos de ápice acuminado e base atenuada.

Sugere-se para trabalhos futuros a avaliação da germinação de H. speciosa em diferentes substratos, para verificar seu desenvolvimento e potencial germinativo.

\section{Agradecimentos}

Ao apoio financeiro do projeto "Serviços ambientais em áreas de mangabeira (Hancornia speciosa Gomes) nas savanas do Amapá: armazenamento de carbono e produção de frutos" (Edital: Chamada pública FAPEAP nº 001/2017 Programa Primeiros Projetos - PPP) e a Universidade do Estado do Amapá.

\section{Referências}

Almeida, 1., Nogueira, c. A., Borges, p. P., Prado, a. D. L., \& Gonçalves, P. J. (2016). State of the art of scientific literature on Hancornia speciosa: Trends and gaps. Revista Brasileira de Fruticultura, 38. doi: https://doi.org/10.1590/0100-29452016869

Barroso, G. M., Morim, M. P., Peixoto, A. L., \& Ichaso, C. L. F. (2004). Frutos e sementes: morfologia aplicada à sistemática de dicotiledôneas. Viçosa: Ufv, 1 .

Brasil. Ministério da Agricultura, Pecuária e Abastecimento. Secretaria de Defesa Agropecuária. (2009). Regras para análise de sementes.

Camargo, J. L. C., Ferraz, I. D. K., Mesquita, M. R., Santos, B. A., \& Brum, H. D. (2008). Guia de Propágulos e Plântulas da Amazônia-Volume 1 (ISBN 978 85-211-0041-6).

Carvalho, M. R. T. D., Bordignon, R., Ballvé, R., Lizana, M., Pinto-Maglio, C. A. F., \& Medina Filho, H. P. (1997). Aspectos biológicos do reduzido número de sementes da tangerina'Sunki'. Bragantia, 56, 69-77. doi: https://doi.org/10.1590/S0006-87051997000100007

Costa-Neto, S. V., Miranda, I., Rocha, A. E. S., Bastos, A., Miranda-Júnior, J., \& Silva, R. (2017). Flora das savanas do estado do Amapá. Bastos A, MirandaJúnior J, Silva R (Eds) Conhecimento e manejo sustentável da biodiversidade amapaense. Blucher, São Paulo, 65-94.

Cruz, E. D., Carvalho, J. E. U. D., \& Leão, N. V. M. (2001). Métodos para superação da dormência e biometria de frutos e sementes de Parkia nitida Miquel. (Leguminosae-Mimosoideae). Acta Amazônica, 31, 167-167. doi: https://doi.org/10.1590/1809-43922001312177

Cruz, E. D., \& Carvalho, J. E. U. D. (2003). Biometria de frutos e sementes e germinação e curupixá (Micropholis cf. venulosa Mart. \& EichlerSapotaceae). Acta Amazônica, 33(3), 389-398. Doi: https://doi.org/10.1590/S0044-59672003000300005 
Duke, J. A. (1965). Keys for the identification of seedlings of some prominent woody species in eight forest types in Puerto Rico. Annals of the Missouri Botanical Garden, 52(3), 314-350. doi: https://doi.org/10.2307/2394796

Ferreira, E., \& Sampaio, E. (2005). Espécies da flora nordestina de importância econômica potencial.

Ferro, J. H. D. A., De Lemos, E. E. P., Fröellich, Â., Sousa, J. D. S., \& Faustino, G. D. L. (2015). Caracterização morfológica dos frutos de mangaba (Hancornia speciosa Gomes) produzidos em Alagoas. Revista Ciência Agrícola, 13(1), 61-67.

Freitas, A. C. (2012). Mangaba (Hancornia speciosa Gomes): Localização de populações nativas no cerrado amapaense e caracterização morfológica das progênies do banco ativo de germoplasma da EMBRAPA Amapá. 2012. 79 f (Doctoral dissertation, Dissertação de Mestrado em Desenvolvimento Regional, Universidade Federal do Amapá (UNIFAP))

Freitas, A. D. D. D. (2008). Aspectos tecnológicos e moreoanatômicos de sementes maduras, lântulas e plantas jovens de Aspidosperma spruceanum Benth. Ex mull. arg.(Apocynaceae).

Ganga, R. M. D. (2008). Variabilidade de plantas e progênies de populações naturais de Hancornia speciosa Gomes do Cerrado.

Ganga, R. M. D., Ferreira, G. A., Chaves, L. J., Naves, R. V., \& Nascimento, J. L. D. (2010). Caracterização de frutos e árvores de populações naturais de Hancornia speciosa Gomes do cerrado. Revista Brasileira de Fruticultura, 32, 101-113. doi: https://doi.org/10.1590/S0100-29452010005000019

Gonçalves, L. G. V., Andrade, F. R., Junior, B. H. M., Schossler, T. R., Lenza, E., \& Marimon, B. S. (2013). Biometria de frutos e sementes de mangaba (Hancornia speciosa Gomes) em vegetação natural na região leste de Mato Grosso, Brasil. Revista de Ciências Agrárias, 36(1), 31-40. doi: https://doi.org/10.19084/rca.16280

Gusmão, E., de Almeida Vieira, F., \& da Fonseca Júnior, É. M. (2006). Biometria de frutos e endocarpos de murici (Byrsonima verbascifolia Rich. ex A. Juss.). Cerne, 12(1), 84-91.

IBGE. (2012). Manual Técnico da Vegetação Brasileira: Sistema fitogeográfico, inventario das formações florestais e campestres, Técnicas e manejo de coleções botânicas, Procedimentos para mapeamentos. Rio de Janeiro: IBGE, 275 p.

Lederman, I. E. (2000). Mangaba (Hancornia speciosa Gomes). Funep.

Lima, I. L. P., \& Scariot, A. (2010). Boas práticas de manejo para o extrativismo sustentável da Mangaba.

Lúcio, D. D. M., Silva, R. A. R., Das Chagas, K. P. T., \& Vieira, F. D. A. (2019). Biometry of fruits and seeds of Hancornia speciosa Gomes (Apocynaceae) in natural populations. Agriculture \& Forestry/Poljoprivreda i Sumarstvo, 65(1). doi: https://doi.org/10.17707/AGRICULTFOREST.65.1.11

Matheus, M. T., Freitas, A.R., Lopes, J.C (2008). Classificação de espécies florestais quanto à morfologia da germinação. XIV Encontro Latino Americano de Iniciação Científica e X Encontro Latino Americano de Pós-Graduação - Universidade do Vale do Paraíba.

Monachino, J. (1945). Uma revisão de Hancornia (Apocynaceae). Lilloa, 19-48.

Mota, D. M. D., Schmitz, H., Silva Júnior, J. F. D., Porro, N. M., \& Oliveira, T. C. V. D. (2014). As catadoras de mangaba no Programa de Aquisição de Alimentos-PAA: um estudo de caso em Sergipe' ${ }^{1}$ Revista de Economia e Sociologia Rural, 52, 449-470.

Moura, C. F. H., Alves, R. E., Filgueiras, H. A. C., Araújo, N. C. C., \& Almeida, A. S. (2002). Quality of fruits native to latin america for processing: mangaba (Hancornia speciosa Gomes). Acta Horticulturae. doi: https://doi.org/10.17660/ActaHortic.2002.575.64

Moura, R. C. D., Lopes, P. S. N., Brandão Junior, D. D. S., Gomes, J. G., \& Pereira, M. B. (2010). Biometria de frutos e sementes de Butia capitata (Mart.) Beccari (Arecaceae), em vegetação natural no Norte de Minas Gerais, Brasil. Biota Neotropica, 10, 415-419.

Muniz, A. D. S., da Vitória, M. F., Nascimento, A. L. S., Ledo, A. D. S., Macedo, L. F. M., Muniz, E. N., \& da Silva Junior, J. F. (2019). Morphological and physicochemical descriptors for characterization of mangaba tree germplasm. Embrapa Tabuleiros Costeiros-Artigo em periódico indexado (ALICE). doi: 10.5039/agraria.v14i2a5645

Nascimento, R. S., Cardoso, J. A., \& Cocozza, F. D. (2014). Caracterização física e físico-química de frutos de mangabeira (Hancornia speciosa Gomes) no oeste da Bahia. Revista Brasileira de Engenharia Agrícola e Ambiental, 18, 856-860. doi: https://doi.org/10.1590/1807-1929/agriambi.v18n08p856-860

Nunes, V. V. (2018). Caracterização e conservação de sementes de mangaba (Hancornia speciosa Gomes). 81 p.

Oliveira, M. E. B. D., Bastos, M. D. S. R., Feitosa, T., Branco, M. A. D. A. C., \& Silva, M. D. G. G. D. (1999). Avaliação de parâmetros de qualidade físicoquímicos de polpas congeladas de acerola, cajá e caju. Food Science and Technology, 19, 326-332. doi: https://doi.org/10.1590/S0101-20611999000300006

Pedrada, T., \& Santos, M. (2014). Uma análise dos cenários e desafios da logística de escoamento do grão de soja do Estado do Mato Grosso em direção ao Estado do Amapá. Revista de Ciências da Amazônia, Macapá, (2), 01-08.

Pedron, F. D. A., Menezes, J. P., \& Menezes, N. L. D. (2004). Parâmetros biométricos de fruto, endocarpo e semente de butiazeiro. Ciência Rural, 34(2), 585586. doi: https://doi.org/10.1590/S0103-84782004000200040

Vieira, R. F., Agostini-Costa, T. D. S., Silva, D. D., Sano, S. M., \& Ferreira, F. R. (2010). Frutas nativas da região Centro-Oeste do Brasil. Embrapa Informação Tecnológica.

Perfeito, D. G. A., Carvalho, N., Lopes, M. C. M., \& Schmidt, F. L. (2015). Caracterização de frutos de mangabas (Hancornia speciosa Gomes) e estudo de processos de extração da polpa. Revista de Agricultura Neotropical. doi: 10.32404/rean.v2i3.269

Pinheiro, E. A., Coimbra, R. R., Silva, K. L. F., \& Ferreira, W. D. M. (2018). Characterization and phenotypic variability in natural populations of mangabeira in the state of tocantins, brazil1. Revista Caatinga, 31, 560-571. doi: https://doi.org/10.1590/1983-21252018v31n304rc 
R Core Team (2020). R: A language and environment for statistical computing. R Foundation for Statistical Computing, Vienna, Austria. URL https://www.Rproject.org/.

Rabelo, H. A., Silva, K. L. F. (2015). Caracterização morfo-anatômica de população natural de mangabeira (Hancornia speciosa Gomes, 1812$)$. 11 Seminário de iniciação científica da uft. V.7.

Santos, L. A., Barros, A. P. G., Hornke, N. F., Karina, A., do Carmo Ferreira dos Santos, P., da Rosa, S., ... \& Pimenta, A. C. (2018). Caracterização Biométrica E Morfológica De Frutos E Sementes E Efeito De Concentrações De Ga3 Sobre A Germinação De Sementes De Mangaba. Global Science And Technology, 11(3).

Santos, C. (2007). Estatística descritiva. Manual de auto-aprendizagem, 2.

Santos, G. R., Melo Ferreira, W., \& Coimbra, R. R. (2021). Seed germination in natural populations of Hancornia speciosa. Diversitas Journal, 6(1), 376-395. doi: https://doi.org/10.17648/diversitas-journal-v6i1-1444

Santos, F. S., De Paula, R. C., Sabonaro, D. Z., \& Valadares, J. (2009). Biometria e qualidade fisiológica de sementes de diferentes matrizes de Tabebuia chrysotricha (Mart. Ex A. DC.) Stand I. Scientia Forestalis/Forest Sciences, 163-173.

Soares, F. P., Paiva, R., Nogueira, R. C., Oliveira, L. M. De, Silva, D. R. G., Paiva, P. D De O. (2005). Cultura da mangabeira (Hancornia speciosa Gomes). Boletim Agropecuário, 67, 1-12. UFLA.

Souza, V. C, \& Lorenzi, H. (2005). Botânica sistemática: guia ilustrativo para identificação das famílias de Angiospemas da flora brasileira, baseado em APG II. Nova Odessa: Instituto Plantarum, 640p.

Tabarelli, M., Vicente, A., \& Barbosa, D. C. A. (2003). Variation of seed dispersal spectrum of woody plants across a rainfall gradient in north-eastern Brazil. Journal of Arid Environments, 53(2), 197-210. doi: https://doi.org/10.1006/jare.2002.1038

Vidal, W. N., \& Vidal, M. R. R. (2006). Botânica-organografia. 8 a impressão. UFV, Viçosa. 67p.

Vieira, F. D. A., \& Gusmão, E. (2008). Biometria, armazenamento de sementes e emergência de plântulas de Talisia esculenta Radlk.(Sapindaceae). Ciência e agrotecnologia, 32, 1073-1079.

Vieira, M.C. 2011. Caracterização de frutos e de sementes de mangabeira (Hancornia speciosa Gomes). Universidade Federal de Goias, Dissertação (Mestrado), Escola de Agronomia e Engenharia de Alimentos. 182 p.

Vieira, M. D. C., Naves, R. V., Moreira, J. P., Souza, E. R. B. D., Paulo, M. D. S. P., Leandro, W. M., \& Moura, N. F. (2017). Biometria de frutos de Hancornia speciosa (Gomes) de ocorrência natural no Cerrado do Estado de Goiás. Volume 34, Pags. 99-109. doi: https://doi.org/10.36560/1012017385

Yokomizo, G. K. I., \& do Nascimento Costa, L. (2016). O uso do cerrado amapaense e os recursos vegetais. DRd-Desenvolvimento Regional em debate, 6(3), 164-177. doi: https://doi.org/10.24302/drd.v6i3.1122

Zuffo, A. M., Gonçalves, L. G. V, Andrade, F. R., Souza, T. R. S., Marimon-Junior, B. H. Biometria de sementes de mangaba (Hancornia speciosa Gomes). IV ENAAG-Encontro Amazônico de Agrárias, v. 4, 2012.

Zuffo, A. M., Busch, A., Steiner, F., Alves, C. Z., de Alcântara Neto, F., de Abreu dos Santos, M., ... \& dos Santos, A. S. (2019). Biometric characteristics of fruits, seeds and plants of 'Hancornia speciosa' Gomes.(Apocynaceae). Australian Journal of Crop Science, 13(4), 622-627. doi: 10.21475/ajcs.19.13.04.p1651 